\title{
E-Blood Bank Application For Organizing and Ordering The Blood Donation
}

\author{
Lilik Sumaryanti ${ }^{1}$, Suwarjono ${ }^{2}$, Lusia Lamalewa ${ }^{3}$ \\ Informatics Engineering Department \\ Universitas Musamus \\ Merauke, Indonesia \\ ${ }^{1}$ lilik@unmus.ac.id, ${ }^{2}$ suwarjono@unmus.ac.id, ${ }^{3}$ lusia@unmus.ac.id
}

\begin{abstract}
Blood Transfusion Unit (BTU) is a blood bank of Indonesian Red Cross (IRC) which duties are to give service, collect blood donation, store and distribute blood according to the request of people in need. Administration process of BTU Merauke is in trouble due to conventional blood donation data management. Therefore, it difficult to specify the number of blood bag in BTU. Also, people who need blood donation must come to BTU office. E-Blood Bank Application is an information system which used to organize blood donation data and order blood online. The application is developed electronically so that it can provide information on blood stock in real time and connect it to BTU, people who need blood donors, and the donor community. Hence, blood stock information can be accessed through easily accessed media at any time and anywhere as long as it is connected to the network. Based on the result of implementation and testing application, it can be concluded that organizing blood donor data electronically through application may present real time blood stock, donor history and order blood bag online. Thus, it helps the service of BTU to people.
\end{abstract} Donor.

Keywords: Electronic System; Blood Bank; BTU; Blood Stock;

\section{INTRODUCTION}

Blood Transfusion Unit (BTU) is the blood bank of Indonesian Red Cross (IRC) which duty is giving service in form of collecting blood donation. Blood donor is an activity to donate blood as volunteer or substitution and then it is distributed to the people in need. In blood donor activity, BTU is responsible to provide services start from administration process, donor condition check, blood transfusion process, until blood storage and blood stock information based on blood type. The administration process other than collecting blood donation is organizing data and confirming blood request. To fulfill blood transfusion, patient's family must come to BTU office with a statement letter from hospital along with requested blood sample as requirement of blood request. If the requested blood is available, BTU will fulfill the request. Yet, if it is not available, BTU will recommend to looking for another donor.

A good service is one of important factor for BTU to run their responsibility. Nevertheless, there is a trouble in which they cannot give real time blood stock information to people and the service only can be done through visiting BTU office. The problem arises due to conventional administration process. In order to make the service better, the process may be applied or conducted through technology development such as develop
E-blood application to process blood data and request electronically. The application aims to make people easier in accessing real time blood stock information without visiting BTU office. The application can connect related parties which are staff/experts in BTU, people in need, and donor community as if they are in the same room. Blood donor data processing and blood request that are done electronically may result in accurate blood stock information and may be accessed at anytime and anywhere as long as there is a network.

Service quality improvement using Application for Online Blood Donation System is a method to synchronize donor and user through internet. Registered users on the application may see donor availability and can sent request to the donor according to blood need and order it by online [1]. Blood Bank is a result of blood donor or collecting blood through donation activity which are saved and preserved for later use in blood transfusions. Blood Bank System Management Using Cloud computing, which is developed as SMS mobile based blood management system for rural area that connected to server cloud in another location, may give information for donor finder about blood availability in another blood bank [2]. Raspberry-Pi Based Embedded Blood Donating Application is developed to bring volunteer blood donor to particular place. It is aimed to fulfill every blood request using Android application which is expected to reduce time span between donor and receiver [3].

Medical science advancement has increased the need of blood such as when doing treatment or operation. The development of Blood Donor Application is used to handle emergency situation of blood availability. The application provides donor detail information and if someone needs blood donor fast so they can contact the donor according to blood type in application [4]. Automatic Blood Bank System connects volunteer blood donor and people in need within public platform. The system connects receiver and the donor by doing direct communication through Direct Call Routing Technique [5]. The application is designed to provide all blood type information and donor contact. The system will connect blood bank and donor by sending message to the donor who has the same blood type with the patient $[6,7]$. The system provides searching feature and display the nearest donor to fulfill the blood need by tracking the location of donor (volunteer) through GPS or cellular network location [8, 10]. Automatic Blood Bank aims to provide direct call routing technique using Asterisk hardware. Blood bank database is made by collecting detail from every source such as blood 
bank, non-governmental organization, hospital, and web interface [9]. Online blood bank system using Android which used to choose nearest hospital is developed to make users see the nearest hospital and blood bank information [10, 11, 12]. Android based E-Blood Bank makes the users possible to search donor according to the blood type in their location and in a short time. This application does not only show donor list but also tracks the nearest donor location [13].

\section{METHOD}

Development system method of E-Blood Bank Application is done based on stages in development system life cycle. It aims to process blood donation data and order blood donor by online. The stages are shown on Figure 1.

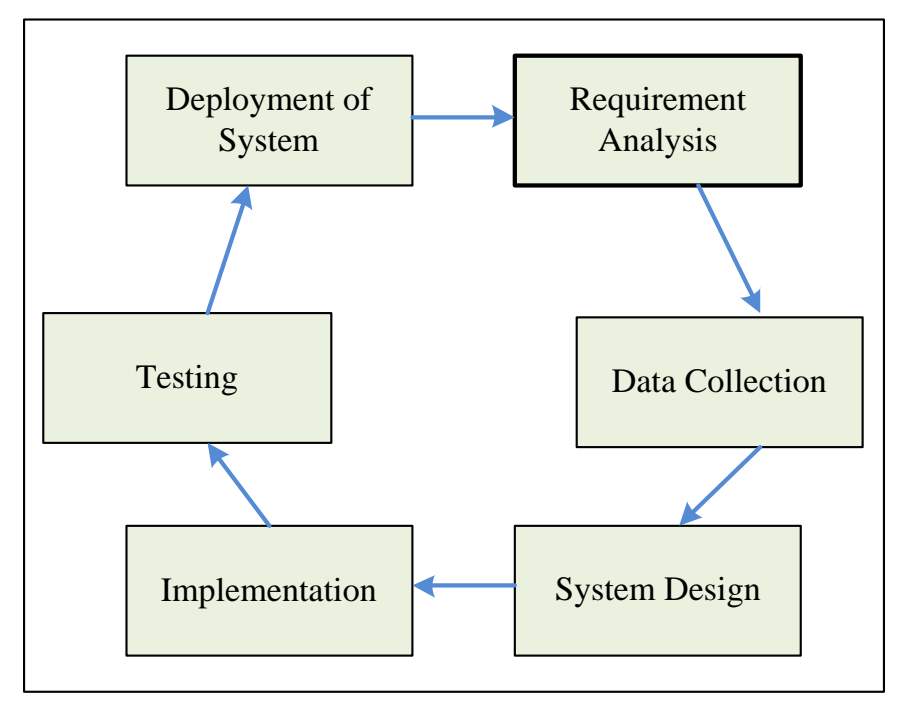

Fig. 1. Research methodology

Research method in Figure 1 consists of several stages as follows:

1. Requirement Analysis is an activity to analyze the need of users and the complete system. Thus, the data for application development are obtained. Users' identification consists of; Blood donation service officer, Blood Orders Officer and donor finder (user). The determination of users' need is differentiated appropriate with identified user level and then determines the system need in form of input/output.

2. Data Collection. Collect the data according with the need of users and system such as profile and contact of the donor, patient data, blood donation transaction activity, blood type, donor reservation data, donor examination result, available blood stock information.

3. System Design, design is done after the needs are completed. System design consists of process/case design using United Modeling Language (UML), Entity Relationship Diagram (ERD) design, Activity Diagram design, system architecture design, form input/output design and reports design.
4. Implementation is a stage to create program and translate it into codes using language programming that has been determined. The program is directly tested in unit.

5. Testing is units' assembly activity and then it tested as a whole. The testing aim to discover whether the program already appropriate with system functional needs that has been determined.

6. Deployment of System is an activity to operate and maintenance program such as adjusting or changing due to the actual condition.

The development of E-Blood Bank Application is expected to help increasing BTU service quality in organizing blood donation data and blood order by online. To know if the application already appropriate with research purposes, questionnaire of the research will be distributed. The questionnaire contains many questions related to system application. This method is used to obtain information of satisfaction which is provided by system.

\section{RESULT AND DISCUSSION}

\section{A. System Architecture}

System Architecture is used to draw or depict the relationship between system components. The relationship between components will show each functional role. On system architecture of E-blood bank application, there are three users which involved. They are, user as donor information finder, blood orders officers whose duty to confirm blood order by users, and Blood Donation service officer whose duty to process blood donation activity data. System Architecture is shown on Figure 2.

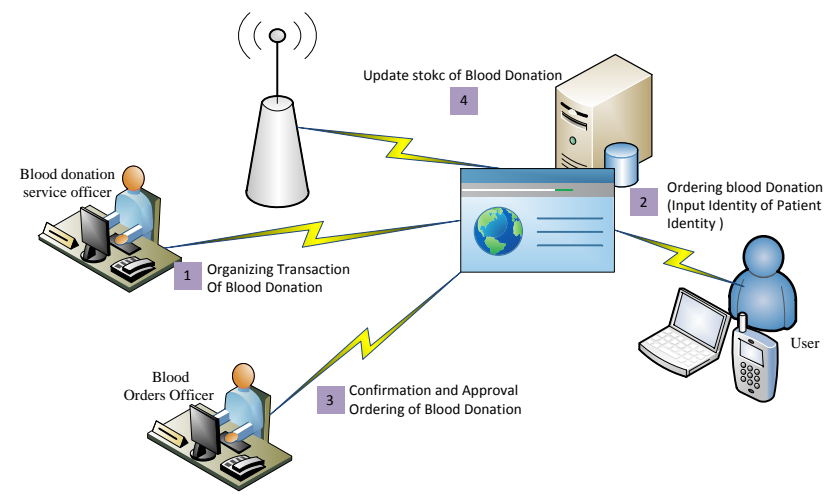

Fig. 2. E-Blood bank application architecture

\section{B. Proposed System for Blood Order Process}

Blood donor order method on the current system is only can be done by visiting BTU office, on the proposed system, order method can be conducted by online. Through this changing, blood donor order or reservation may be conducted at anytime and anywhere as long as the users are connected to the internet and access E-blood bank. The online order method is aims to obtain update blood stock information on blood bank in real time. Figure 3 shows flowchart of blood order process on the proposed system. The system gives feature to looking 
for information on available blood stock on the blood bank based on blood type as searching category. If the blood stock still available, the system will show the form for patient data input. Afterward, data verification process will be conducted by Blood orders Officer.

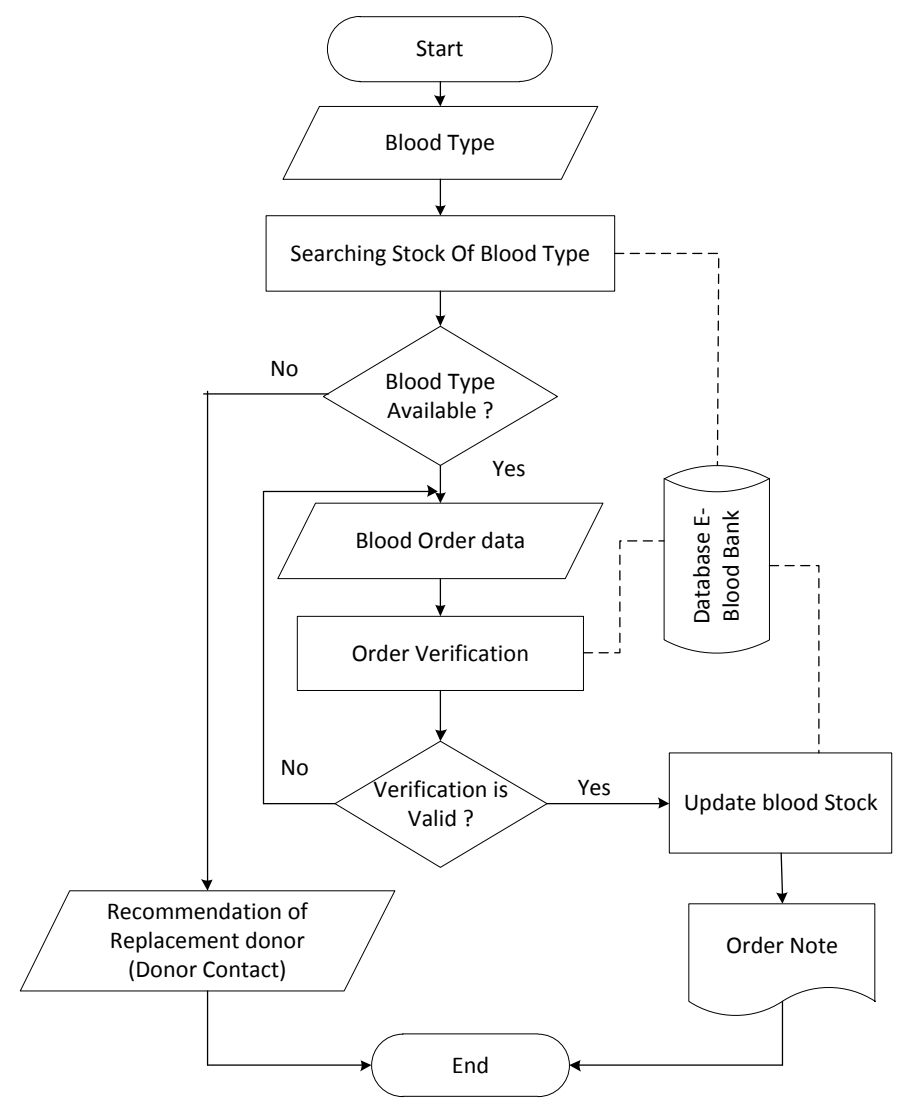

Fig. 3. Order process flowchart

\section{Use Case Diagram}

Use Case diagram is used to draw interaction between system, external system and user. Use case diagram describes who will use the system and how the user expects interaction with the system. System use within UML is called actor. There are three users which are user (donor finder), Blood Orders Officer and Blood Donation Service Officer. The next stage is to find use case. The formation of use case starts from finding information from the actor. Figure 4 shows the role of three actors or user. User is someone who searching for blood and orders it. Blood Donation Service Officer has a role to manage the data of blood donation transaction, master data, and can access related report with blood donation, also donor history. Meanwhile, Blood Orders Officer has the role to confirm blood donor order by user. The verification is done based on patient data and statement letter from hospital that the patient needs blood donor. The form is uploaded when fill the order form in application. The transaction process of donor and order of blood will automatically update blood stock in bank blood in real time.

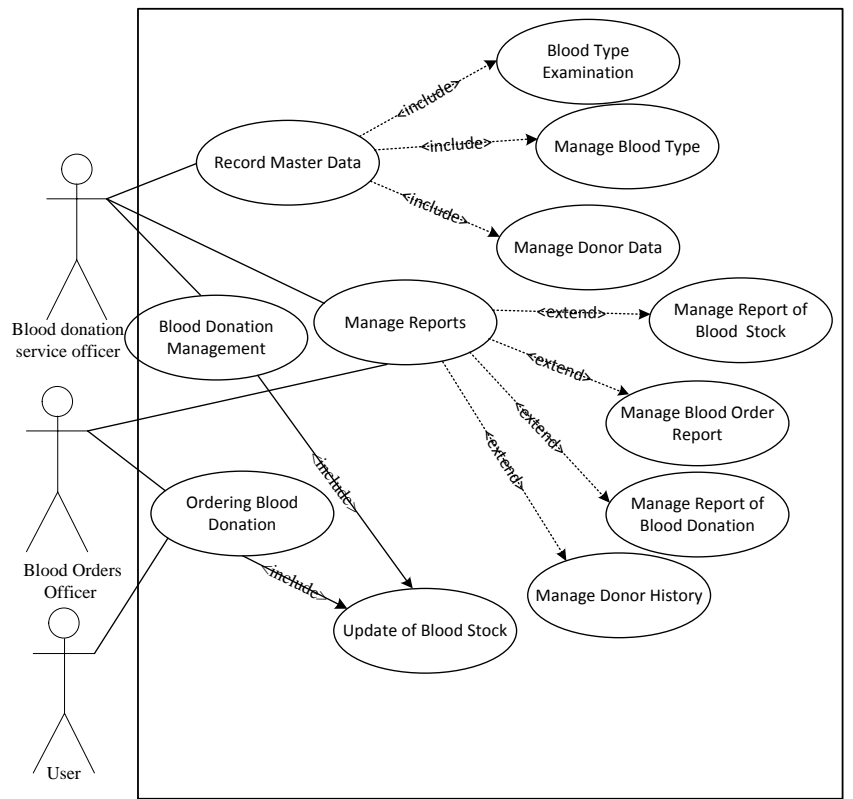

Fig. 4. Use Case System Diagram

\section{System Testing Result}

System testing is the most important part of system development cycle. The aim is to detect system failure. Consequently, faulty can be repaired in the initial phase. System testing is confirmation process of product/system by programmer which state that the program have quality and run based on specification. E-Blood bank application testing uses black box method. It is used to know whether the system can run properly according to functional system need that has been determined. How internal system testing techniques work is not known by tester. In example, in testing black box on Application Under Test (AUT), tester only knows the input and does not what will be the output, without knowing how the program works in producing output [14].

Table 1 shows the need of functional system that has been tested after system implementation stage. If the functional system need is fulfilled by application, so in column it marked Yes $(\sqrt{ })$. Nevertheless, if it is vice versa, in column it marked No $(\sqrt{ })$. 
TABLE I. BLAck Box Testing For Functional System REQUIREMENT

\begin{tabular}{|c|l|c|c|}
\hline No & \multicolumn{1}{|c|}{ Functional System Requirement } & Yes & No \\
\hline 1 & $\begin{array}{l}\text { System can process the data of blood donation } \\
\text { transaction }\end{array}$ & $\sqrt{ }$ & - \\
\hline 2 & System gives feature to manipulate the master data & $\sqrt{ }$ & - \\
\hline 3 & $\begin{array}{l}\text { System may shows information of contact and } \\
\text { donor history }\end{array}$ & $\sqrt{ }$ & - \\
\hline 4 & System can run donor order transaction & $\sqrt{ }$ & - \\
\hline 5 & $\begin{array}{l}\text { System provides feature to verify blood donor } \\
\text { order }\end{array}$ & $\sqrt{ }$ & - \\
\hline 6 & $\begin{array}{l}\text { System provides searching information feature of } \\
\text { blood stock based on certain blood type }\end{array}$ & $\sqrt{ }$ & - \\
\hline 7 & $\begin{array}{l}\text { System can update blood stock automatically when } \\
\text { there is blood donation transaction or blood donor } \\
\text { order }\end{array}$ & $\sqrt{ }$ & - \\
\hline 8 & $\begin{array}{l}\text { System can be used to documented blood } \\
\text { examination result }\end{array}$ & $\sqrt{ }$ & - \\
\hline 9 & $\begin{array}{l}\text { System can show donor contact information and } \\
\text { blood type }\end{array}$ & $\sqrt{ }$ & - \\
\hline 10 & $\begin{array}{l}\text { System give feature to make report of blood } \\
\text { donation report and blood stock }\end{array}$ & $\sqrt{ }$ & - \\
\hline 11 & $\begin{array}{l}\text { System can show blood daily, monthly, or annual } \\
\text { order report }\end{array}$ & $\sqrt{ }$ & - \\
\hline
\end{tabular}

Questionnaire testing method also conducted to obtain users satisfaction on information within the system. Usability becomes a factor that influence an application can be said as good or bad by using USE questionnaire which contain of 4 parameters which are usefulness, ease of use, ease of learning and satisfaction [15]. The questionnaire has 30 questions and divided into 4 parameters. Each statement represents assessment when using the application. There are 3 aspects of usability measure in this questionnaire which are effectiveness, efficiency, and satisfaction. To conduct this research, the researcher uses 5 points scales with Likert scale method. Each point consists of strongly agree, agree, neutral, disagree, and strongly disagree. Then, determine the users group based on age gap. This research uses two user groups, they are college students (18-24 years old) and adults (25-64 years old). The questionnaire is distributed to 500 respondents with each group user in amount of 250 respondents. The calculation process of four parameter attributes are usefulness, ease of use, ease of learning and satisfaction using 5 points Likert scales in Figure 5. It is aimed to know the comparison of each parameter.

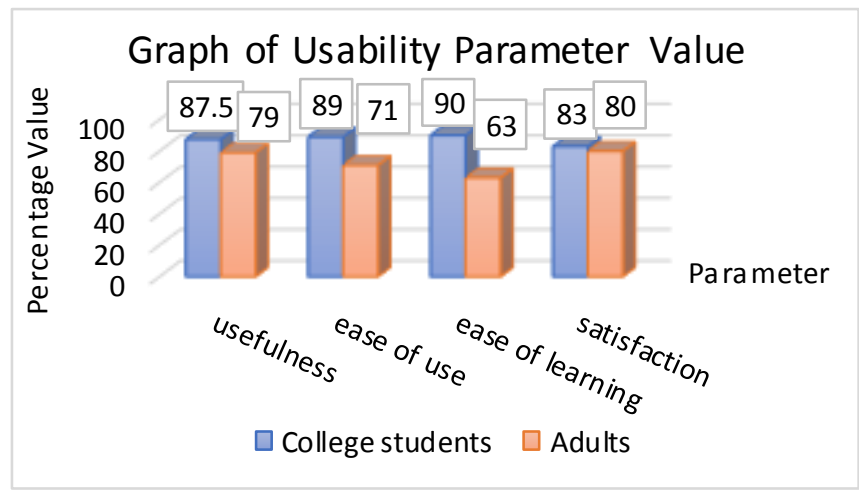

Fig. 5. Comparison of Usability of Each Parameter

To obtain usability value of certain application, it needs usability value in each parameter to be found its average. The calculation uses equation 1 .
Score $=\frac{\text { usefulness }+ \text { ease of use }+ \text { ease of learning }+ \text { satisfication }}{4}$

The result of usability comparison value for two user groups is college students $87.35 \%$ and adults $73.25 \%$. The usability value shows that E-Blood Bank Application can help BTU to increase their blood donation service.

\section{CONCLUSION}

The result of E-Blood Bank Application implementation is aimed to process blood donation data and order blood by online. After passing the testing stage, it can be concluded that:

1. E-Blood Bank Application has several service features. They are donor data process, donor history, blood order by online, data processing of blood type examination, blood donation data transaction process, and real time blood stock information.

2. Application testing using blackbox method shows that the application is already appropriate with determined functional system. For questionnaire testing, it is done to 500 respondents which are grouped into two groups, college students and adults. It produces usability value college students $87.35 \%$ and adults $73.25 \%$. Therefore, it can be concluded that the application may help increasing blood donation service in BTU.

\section{REFERENCES}

[1] D. Hegde, A. Kuriakose, A. Mariya, A. Philip, and A.P. Abraham, "Design and Implementation of E-Blood Donation System Using Location Tracking," Int. J. Innov. Res. Comp. Commun. Eng., vol. V, pp. 9293-9298, 2017.

[2] J.K. Akhtar and M.R. Alony, "A New Concept of Blood Bank Management System using Cloud Computing for Rural Area (INDIA)," Int. J. Electr. Comp. Eng., vol. IV, pp. 20-26, 2015.

[3] M.G. Pratyusha, P.V.V.N.D.P. Sunil, K. Tejaswi, P. Kanakaraja, Y.S. Ramya, "Raspberry-Pi Based Embedded Blood Donating Application," Int. J. Innov. Res. Sci. Eng. Tech., vol. V, pp. 5679-5685, 2016.

[4] K. Yamini and R. Devi, "Optimization of Blood Donor Information and Management System," Int. J. Innov. Res. Sci. Eng. Tech., vol. V, pp. 11713-11716, 2016.

[5] J.A. Rupsanth and P. Marikkannu, "Automated Blood Bank Management System Using Direct Call Routing Technique," Int. J. Nov. Res. Comp. Sci. Softw. Eng., vol. III, pp. 107-111, 2016.

[6] A. Alkandari, F.E. Alkandari, and A. Alshammari, "Blood Bank Smart Phone Application for Managing and Organizing the Blood Donation," Int. J. New Comp. Archit. Appl., vol. VI, pp. 86-91, 2016.

[7] A. Tayal, H. Gahare, A. Patel, S. Jog, P. Jain, and J. Dhawale, "A Survey on Blood Bank Management System," Int J. Recent Trends Eng. Res., vol. III, pp. 136-138, 2017.

[8] S. Parikh, P. Kathiria, Y. Vaghela, H. Shah, and D. Dholakiya, "A GeoLocation based Mobile Service that Dynamically Locates and Notifies the nearest Blood Donors for Blood Donation during Medical Emergencies," Int. J. Comp. Appl., vol. VIII, pp. 33-39, 2014.

[9] G. Devilal and V. Kumar, "Automated Blood Bank," Int. J. Mag. Eng. Tech. Manag. Res., vol. III, pp. 872-881, 2016.

[10] S.V. Anabhavane, P. Lokhande, S. Kasar, and P. More, "Android Blood Bank," Int. J. Adv. Res. Comp. Commun. Eng., vol. IV, pp. 86-88, 2015.

[11] A. Jain, A. Nirmal, N. Sapre, and S. Mone, "Online Blood Bank Management System using Android," Int. J. Innov. Stud. Sci. Eng. Tech., vol. II, pp. 55-58, 2016. 
[12] R. Pawar, S. Thigale, P. Walekar, G. Thakar, and D. Joshi, "Optimal Facility for Location Tracking of Blood Bank and Donor," Int. Res. J. Eng. Tech., vol. III, pp. 1325-1330, 2016.

[13] S. Pande, S. Mate, P. Mawal, A. Jambulkar, and N.S. More, "E-Blood Bank Application Using Cloud Computing," Int. Res. J. Eng. Tech., vol. V, pp. 278-281, 2018.

[14] M. Kumar and S.K. Sing, "A Comparative Study of Black Box Testing and White Box Testing Techniques," Int. J. Adv. Res. Comp. Sci. Manag. Stud., vol. III, pp. 32-44, 2015.

[15] K.R. Hadi, H.M. Az-Zahra, and L. Fanani, "Analisis Dan Perbaikan Usability Aplikasi Mobile KAI Access Dengan Metode Usability Testing Dan Use Questionnaire," J. Pengemb. Teknol. Inf. Ilmu Komput., vol. II, pp. 2742-2750, 2018. 